\title{
ANALISIS STUDI KELAYAKAN USAHA CHRISTINE KLAPPERTAART DI KAIRAGI WERU MANADO
}

\author{
Yestelin Kawoka \\ Ventje V. Rantung \\ Caroline B.D Pakasi
}

\begin{abstract}
This study aims to determine the feasibility of Christine klapertaart in terms of non financial aspect and financial aspects.The result showed that non financial feasibility analysis shows Christine klapertaart feasible to proceed with supported aspects. Financial feasibilty analysis with 100 own capital is feasible with NPV value at df 18\%., IRR is more than prescribed interest rate 18\%, the value Profitability Index more than 1. Payback period shows that this business have returned investment within 2 years and 6 months 27 days.
\end{abstract}

Keywords: Feasibility study, business, klappertaart, Kairagi Weru, Manado

\begin{abstract}
ABSTRAK
Penelitian ini bertujuan untuk mengetahui kelayakan usaha Chistine klappertaart ditinjau dari aspek non financial dan aspek financial. Hasil penelitian menunjukkan bahwa analisis kelayakan non financial menunjukan usaha Christine klappertaart layak untuk dilanjutkan dengan adanya aspek-aspek yang menunjang usaha ini. analisis kelayakan financial dengan 100\% modal sendiri dinyatakan layak, dengan nilai net present value yang positif pada diskon factor $18 \%$, internal rate of return lebih besar dari tingkat suku bunga yang ditentukan yaitu 18\%, dengan nilai profitability indeks lebih besar dari satu. payback period menunjukan bahwa usaha Christine klappertaart akan mengembalikan investasinya dalam waktu 2 tahun enam bulan 27 hari.
\end{abstract}

Kata kunci: Studi kelayakan, usaha, klappertaart, Kairagi Weru Manado

\section{PENDAHULUAN}

\section{Latar belakang}

Sektor pertanian mempunyai peranan yang sangat penting bagi perekonomian, peran tersebut dapat dilihat dari kontribusi sektor pertanian dalam hal penyerapan tenaga kerja dan sebagai supply atau pemasok bahan baku bagi sektor industri. sektor pertanian dan industri merupakan sektor yang terkait satu sama lain, dimana pertanian sebagai penyedia bahan baku, sedangkan industri mengelola hasil pertanian untuk memperoleh nilai tambah bagi produk pertanian yang disebut sebagai agroindustri.

Semua usaha pertanian pada dasarnya adalah kegiatan ekonomi sehingga memerlukan dasar-dasar pengetahuan yang sama akan pengelolaan tempat usaha, distribusi produk, pengolahan dan pengemasan produk, dan pemasaran. apabila semua aspek ini menjadi efisiensi untuk mencapai keuntungan maksimal maka usaha pertanian yang dipandang dengan cara ini dikenal sebagai agribisnis. agroindustri 
sebagai suatu usaha untuk menciptakan nilai tambah bagi komoditi pertanian antara lain, melalui produk olahan dalam bentuk setengah jadi maupun barang jadi yang bahan bakunya berasal dari hasil pertanian.

Menurut Andrianto (2010) Agroindustri diartikan sebagai semua kegiatan industri yang terkait erat dengan kegiatan pertanian, dengan demikan macam agroindustri banyak sekali diantaranya industri pengolah hasil-hasil pertanian baik yang sifatnya setengah jadi maupun produk akhir agroindustri mampu meningkatkan pendapatan para pelaku agribisnis, meningkatkan perolehan devisa, dan mampu mendorong munculnya industri yang lain (Aji, 2012). Usahausaha pengembangan pertanian yang mengarah pada kegiatan agroindustri dengan produk yang memiliki daya tarik akan bahan bakunya, proses produksinya, bentuk produknya dan permintaannya adalah agroindustri dengan bahan baku kelapa yang dapat diolah menjadi bahan makanan.

Salah satu usaha yang tergolong agroindustri skala kecil adalah usaha Christine klappertaartyang memanfaatkan hasil pertanian kelapa atau Genus Cocos dengan nama Species Cocos Nucifer L, dalam usaha Chistine klappertaart kelapa sebagai bahan baku dalam pembuatan produk ole-oleh khas manado berupa kue basah klappertaart.

Karena usaha Christine klappertaart ini masih tergolong baru, dengan umur ekonomis yang dimiliki usaha ini masih tiga tahun maka penulis tertarik melakukan penelitian tentang studi kelayakan pada usaha ini dengan melihat aspek-aspek yang mendukung jalannya usaha ini baik aspek non financial maupun aspek financial.

\section{METODE PENELITIAN}

\section{Lokasi dan waktu penelitian}

Penelitian ini dilaksanakan pada industri kecil usaha Christine klappertaart Jalan Yos Sudarso 140 Kairagi Weru Manado.Penentuan lokasi ini dilakukan secara sengaja (purposive) dengan pertimbangan bahwa Christine klappertaartmerupakan usaha agroindustri sebagai oleole khas Manado yang masih tergolong usaha baru untuk dilakukan studi kelayakan dengan tujuan pengembangan usaha yang telah dijalankan sebelumnya. Penelitian ini dilaksanakan selama empat bulan yakni dari bulan April 2015 sampai bulan Juli 2015, mulai dari persiapan proposal sampai penyusunan laporan penelitian.

\section{Teknik dan pengumpulan data}

Dalam penelitian ini data yang dikumpulkan adalah data primer dan data sekunder.data primer adalah data yang diambil oleh peneliti dari sumber utama yakni pemilik usaha Christine klappertaart berdasarkan daftar pertanyaan (kuisioner) dengan teknik wawancara. Sedangkan data sekunder adalah data yang telah tersedia yang dikutip oleh peneliti guna kepentingan penelitiannya.teknik pengumpulan data yang digunakan pada penelitian ini adalah sebagai berikut:

a. Observasi dalam penelitian ini adalah observasi tidak terstruktur, yaitu observasi yang dilakukan dengan tidak menggunakan pedoman pengamatan. Dalam penelitian ini penulis melakukan penelitian secara langsung untuk melihat dan mengamati situasi dan kondisi pada usaha Chtistine klappertaart.

b. Wawancara, yaitu salah satu teknik pengumpulan data dengan melakukan dialog langsung antara peneliti dengan pemilik usaha. sebelum melakukan wawancara peneliti telah mempersiapkan terlebih dahulu kusioner atau daftar pertanyaan yang akan diberikan kepada pemilik usaha tersebut.

c. Studi kepustakaan, yaitu pengumpulan data yang diperoleh dari buku-buku, jurnal, dan sumber-sumber yang terkait dengan penelitian ini. 


\section{Konsep pengukuran variabel}

Adapun variabel yang diukur dalam penelitian ini adalah :

1. Aspek non financial

a. Aspek pasar dan pemasaran (marketing),

b. Aspek teknis dan teknologis (produksi/operasi),

c. Aspek manajemen dan organisasi (SDM),

d. Aspek hukum

e. Aspek keuangan

2. Aspek financial

a. Cash flow

b. Payback period (PP)

c. Net present value (NPV)

d. Internal rate of return (IRR)

e. Profitability index (PI)

\section{Metode analisis data}

Metode analisis data yang digunakan dalam penelitian ini yaitu analisis deskriptif kuantitatif. Analisis deskriptif digunakan untuk menggambarkan aspek non financial di dalam penelitian sedangkan analisis kuantitatif digunakan untuk menilai kelayakan investasi dalam penelitian dengan alat bantu microsoft excel dan menggunakan rumus sebagai berikut :

\section{Payback period}

Payback period atau pengembalian investasi adalah suatu periode atau jangka waktu yang diperlukan untuk dapat menutup kembali investasi menggunakan aliran kas neto proceeds.

Rumus yang digunakan untuk menghitung payback period $(P P)$ adalah sebagai berikut :

payback period $(P P)=\frac{\text { investasi kas bersih }}{\text { aliran kas masuk tahunan }}$

Kriteria penilaian investasi pada payback period adalah : a. Jika payback period < waktu maksimum, maka usulan proyek tersebut dapat diterima.

b. Jika payback period > waktu maksimum, maka usulan proyek tersebut ditolak.

\section{Net present value}

Rumus yang digunakan untuk menghitung net present value (NPV) adalah sebagai berikut : lays

$\mathrm{NPV}=\mathrm{PV}$ dari proceeds $-\mathrm{PV}$ dari out -

PV dari proceeds $=\mathrm{PV}$ dari aliran kas

$\mathrm{PV}$ dari outlays = PVdari total investasi

Kriteria investasi berdasarkan net present value yaitu:

a. NPV > 0, artinya suatu proyek dinyatakan menguntungkan dan dapat dilaksanakan.

b. NPV < 0, artinya proyek tersebut tidak menghasilkan nilai biaya yang dipergunakan, atau dengan kata lain proyek tersebut merugikan dan sebaiknya tidak dilaksanakan.

c. $\mathrm{NPV}=0$, artinya proyek tersebut mampu memberikan tingkat pengembalian sebesar modal sosial opportunities cost faktor produksi normal. dengan kata lain, proyek tersebut tidak untung maupun rugi.

\section{Profitability index (PI)}

Rumus yang digunakan untuk menghitung profitability index (PI) adalah sebagai berikut :

profitability index $(P I)=\frac{\text { Procceds }}{\text { Outlays }}$

$\begin{array}{ll}\text { Keterangan } & : \\ \text { Procceds } & \text { : aliran kas (cash flow) } \\ \text { Outlays } & : \text { total investasi }\end{array}$

Keterangan :

Outlays : total investasi 
Kriteria kelayakan investasi pada profitability ideks :

a. Proyek dinilai layak jika PI $>$ atau $=1,00$, sebaliknya

b. Proyek dinilai tidak layak jika PI $<1,00$

\section{Internal rate of return (IRR)}

Rumus yang digunakan untuk menghitung IRR adalah sebagai berikut :

$$
I R R=\sum_{t=0}^{n}\left[\frac{\mathrm{A}_{\mathrm{t}}}{(1+\mathrm{r})^{\mathrm{t}}}\right]=0
$$

Keterangan :

$\mathrm{r} \quad=$ tingkat bunga yang akan menjadikan PV dari proceeds sama dengan P.V, dari capital outlays

At $=$ cash flow untuk periode $\mathrm{t}$

$\mathrm{n} \quad=$ periode terakhir di mana cash flow diharapkan

atau IRR $=\frac{\text { total laba usaha }}{\text { Modal Sendiri }}$

Kriteria kelayakan investasi internal rate of returnadalah :

a. Jika IRR > dari suku bunga yang telah ditetapkan, maka investai diterima.

b. Jika IRR < dari suku bunga yang telah ditetapkan, maka investasi ditolak.

\section{HASIL DAN PEMBAHASAN}

\section{Deskripsi umum usaha Christine klappertaart}

Christine klappertaart adalah salah satu usaha agroindustri yang bergerak di bidang pengolahan makanan berupa kue basah yang menggunakan kelapa muda sebagai bahan baku utamanya. nama usaha Christine klappertaart diambil dari nama pemilik usaha ini yaitu ibu Christine Samangkud. Usaha Christine klapper- taart merupakan usaha yang baru dengan umur ekonomis yang dimiliki yaitu tiga tahun mulai dari tahun 2012 sampai dengan tahun 2015.

usaha ini bermula dari hobby, kemudian berkembang dengan adanya orderan dari para sahabat dan teman dekat yang berniat mencoba kue basah klappertaart ini, sampai pada akhirnya berkembang hingga penambahan tenaga kerja untuk membuat usaha ini dikomersilkan.

untuk salah satu distribusi yang dilakukan yaitu melalui outlet yang dimiliki oleh usaha ini dengan alamat Jalan Yos Sudarso 140 Kairagi Weru Manado.

\section{Struktur organisasi}

Struktur organisasi dalam usaha Christine klappertaart masih tergolong sederhana.karena pemilik merangkap sebagai direktur utama sekaligus manajer.

Bentuk struktur organisasi pada usaha Christine klappertaart yaitu terdapat pada Gambar 1:

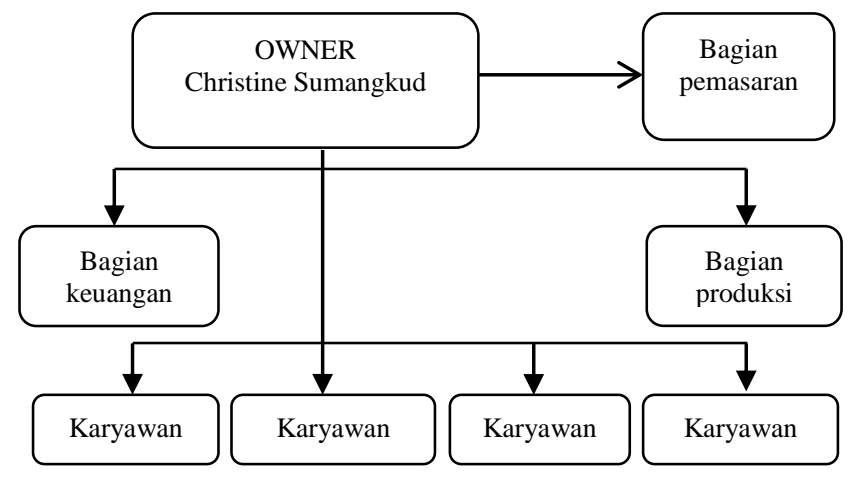

Gambar 1. Struktur organisasi Christine klappetaart

Direktur sekaligus manajer usaha ini mempunyai wewenang mengambil keputusan pada saat tertentu serta yang bertanggung jawab terhadap segala sesuatu yang terjadi dalam usaha yang dijalankan. Peran penting sebagai owner mengontrol mulai dari pembelanjaan, proses produksi, sampai pemasaran, serta mengelolah karyawan yang berjumlah tujuh orang dengan porsi kerja masingmasing.

Adapun tenaga kerja sekaligus merangkap bagian supervisor bertanggung jawab penuh terhadap 
proses produksi yang dipercayakan serta mengontrol jalannya usaha Christine klappertaart. Struktur organisasi yang sederhana dalam usaha ini menjadikan usaha ini dapat dengan mudah dikontrol secara langsung maupun tidak langsung.

\section{Analisis aspek non financial}

\section{Aspek pasar dan pemasaran (marketing)}

Aspek pasar yang diteliti meliputi bauran pemasaran yang terdiri dari 4P yaitu produk (product), harga (price), tempat (place) dan promosi (promotion), yang dijalankan oleh usaha ini.

\section{a. Produk (product)}

Produk utama yang dihasilkan adalah klappertaart dengan bahan baku utama kelapa muda menghasilkan berbagai macam aneka rasa dan ukuran diantaranya terdiri dari 5 rasa yaitu blueberry, coklat, keju, durian dan original dengan ukuran mulai dari kemasan yang paling kecil hingga kemasan yang paling besar dalam setiap kali proses produksi.

\section{b. Harga (price)}

Harga produk klappertaart berbeda-beda, harga klappertaart berdasarkan ukurannya mulai dari Rp15.000 untuk rasa original, Rp17.500 untuk aneka rasa seperti coklat, rasa blueberry, rasa keju dan rasa durian hingga ukuran kemasan yang paling besar dengan harga Rp210.000 per piring.

Tabel 1. Ukuran, aneka rasa dan harga klappertaart

\begin{tabular}{ccc}
\hline No. & Ukuran dan aneka rasa & $\begin{array}{c}\text { Harga per unit } \\
(\mathrm{Rp})\end{array}$ \\
\hline 1. & Kecil original & 15.000 \\
2. & Kecil campuran & 17.500 \\
3. & Sedang original & 65.000 \\
4. & Sedang campuran & 75.000 \\
5. & Besar original & 110.000 \\
6. & Besar campuran & 210.000 \\
\hline 7. & Total & 492.500 \\
\hline
\end{tabular}

\section{c. Promosi (promotion)}

Promosi yang dilakukan adalah dengan melalui penyebaran brosur di lingkungan sekitar usaha, di pusat perbelanjaan, di perumahan, dalam promosi juga menggunakan sosial media berupa internet dan facebook tidak dikenakan biaya promosi. Strategi promosi dalam penjualan juga dilakukan melalui radio dan tv swasta seperti trans7, antv, tv one, RCTI, dan SCTV kecuali tv lokal belum pernah dilakukan.

Biaya promosi yang dikeluarkan dalam usaha ini dilakukan untuk klien baru atau instansiinstansi yang merupakan bagian dari promosi yang dilakukan oleh owner.promosi juga menggunakan pameran maka ada biaya tersendiri yang disediakan, bergabung dengan instansi untuk pameran.dalam satu tahun usaha ini mengeluarkan Rp24.000.000 untuk biaya promosi.

\section{d. Distribusi (distribution)}

Pada umumnya produk yang dihasilkan di distribusikan untuk supermarket seperti Multi Mart dan Indo Maret, selain itu pada outlet yang dimiliki usaha Christine Klappertaart, tetapi yang dipakai sekarang untuk pendistribusian hanya berdasarkan permintaan dengan sistem pemesanan langsung sampai kepada konsumen akhir dengan cara menggunakan transportasi motor dan mobil untuk jarak jauh, sedangkan untuk penawaran klappertaart selalu habis terjual, bahkan ada pembeli yang tidak mendapatkan produk klappertaart karena telah habis terjual.

Biaya yang dikeluarkan untuk mobil yang digunakan adalah Rp100.000 per hari untuk biaya bensin, tetapi biasanya penggunaan yang dilakukan per 3 hari yaitu dengan biaya Rp300.000. Jika menggunakan jasa motor dalam satu kali orderan menggunakan tiga motor biaya yang dikeluarkan sebesar Rp700.000 per bulan sedangkan untuk biaya bahan bakar minyak pada transportasi mobil sebesar Rp2.000.000 per bulan. Jadi rata-rata biaya yang dikeluarkan untuk biaya distribusi untuk motor dan mobil dari sistem pemesanan langsung sampai kepada kon- 
sumen akhir adalah sebesar Rp2.700.000 per bulan. Untuk distribusi yang berlaku sekarang distribusi ke supermarket dihentikan, karena owner hingga tenaga kerja kewalahan dalam proses produksi disebabkan tenaga kerja hanya tujuh orang dengan masing-masing jam kerja.

Adapun rantai distribusi usaha Christine klappertaart seperti yang terdapat pada Gambar 2 :

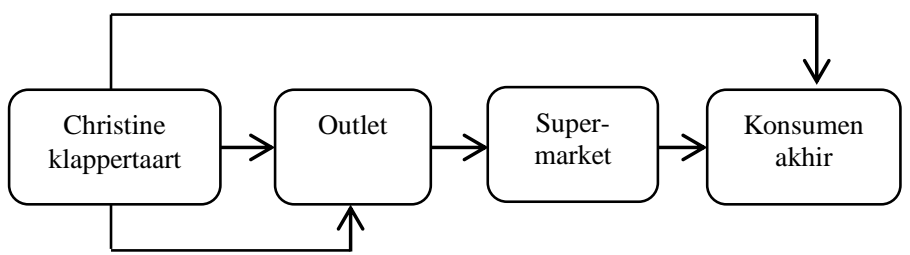

Gambar 2. Rantai distribusi Christine klappertaart

2. Aspek teknis dan teknologis (produksi/operasi)

Lokasi usaha Christine klappertaart cukup strategis karena sarana dan prasarananya menunjang, seperti dekat dengan jalan raya dan perumahan, serta fasilitas umum lainnya, sehingga memudahkan untuk akses pembelanjaan dan pemasaran. Untuk lokasi usaha Christine klappertaart menggunakan outlet yang menggunakan sistem sewa, untuk biaya sewa per bulan sebesar Rp1.500.000 jadi biaya sewa per tahun adalah sebesar Rp18.000.000. untuk tempat produksi klappertaart biaya yang dikeluarkan adalah sebesar Rp100.000.000

\section{a. Bahan baku}

Bahan baku utama untuk membuat klappertaart adalah kelapa, terlebih khusus kelapa muda. Dalam memproduksi klappertaart, usaha ini menggunakan bahan baku lokal yang berasal dari petani langsung khususnya petani yang berasal dari Desa Laikit Minahasa Utara dengan alasan kelapa lokal lebih berkualitas. pemenuhan bahan baku diperoleh dengan cara membeli dengan harga rata-rata Rp13.500 per kg. dalam usaha ini proses produksi biasanya dilakukan rata-rata $45 \mathrm{~kg}$ per 2 hari dengan biaya sebesar Rp607.500. Proses produksi juga tergantung pemesanan, jadi untuk penggunaan bahan baku kelapa muda selama 1 bulan yaitu $585 \mathrm{~kg}$. sehingga untuk biaya yang dikeluarkan selama proses produksi adalah sebesar Rp7.897.500 per bulan.

Proses pembuatan klappertaart juga membutuhkan bahan berupa tepung, gula, telur, susu, kenari, keju, coklat dan durian. durian yang digunakan diperoleh dari medan. rata-rata penggunaan durian selama satu bulan yaitu $40 \mathrm{~kg}$ durian, biaya yang dikeluarkan sebesar Rp100.000 per kg. jadi rata-rata biaya yang dikeluarkan untuk durian adalah sebesar Rp4.000.000 per bulan. Adapun biaya yang dikeluarkan untuk biaya bahan lainnya seperti tepung, gula, telur, coklat dan keju adalah sebesar Rp800.000 per bulan.

\section{b. Tenaga kerja}

Tenaga kerja yang dimiliki oleh usaha Christine klappertaart adalah tujuh orang tenaga kerja.Dengan masing-masing tiga orang tenaga kerja harian dan empat orang tenaga kerja bulanan termasuk supervisor.

\section{c. Teknologi}

Teknologi yang digunakan dalam usaha Christine klappertaart tergolong modern. Mesin dan alat-alat penunjang operasional lain yang dibutuhkan untuk proses produksi hingga menjadi klappertaart adalah oven, tabung, kompor, kulkas dan mesin pengaduk kelapa. adapun biaya mesin dan alatalat penunjang operasional yaitu sebesar Rp20.682.000

\section{d. Proses produksi}

Proses produksi klappertaart dalam usaha Christine klappertaart melalui beberapa tahap mulai dari persiapan bahan baku sampai pada proses pengemasan. Dalam proses pengadukkan tidak menggunakan tenaga kerja karena prosesnya lama sehingga menggunakan mesin pengaduk, dengan kapasitas satu kali aduk kelapa yang dibutuhkan adalah $45 \mathrm{~kg}$ dengan jumlah 180 biji kelapa. 
Berikut adalah tahapan proses produksi klappertaart berdasarkan gambar 3 di bawah ini :

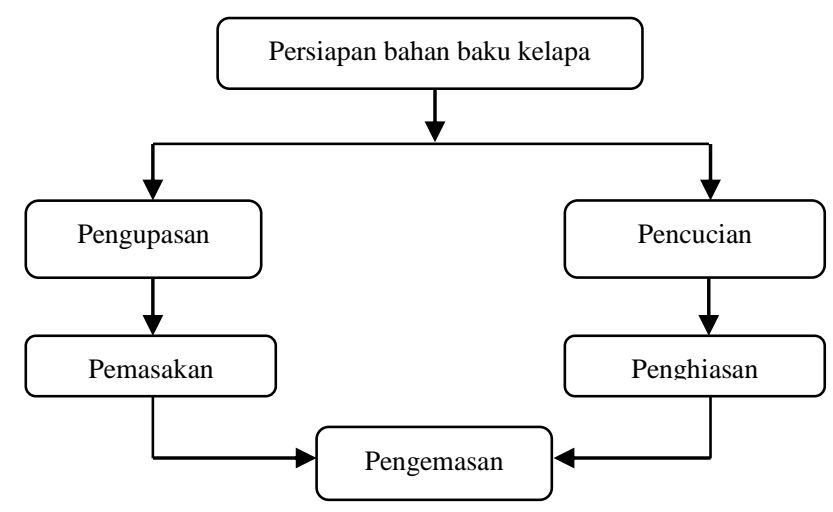

Gambar 3. Proses produksi klappertaart

3. Aspek manajemen dan sumber daya manusia

Aspek manajemen dan sumber daya manusia dalam usaha Christine klappertaart mempunyai sistem manajemen yang bersifat open manajemen.Hal ini dapat dilihat dengan adanya rapat dengan agenda mereview semua pengeluaran dan pemasukan yang terjadi dalam usaha yang dilaksanakan secara rutin satu kali dalam seminggu.

Terdapat dua jenis tenaga kerja yaitu tenaga kerja harian dan tenaga kerja bulanan dengan masingmasing jam kerja, tenaga kerja harian dengan jam kerja mulai pukul 09.00-14.00 WIB dengan upah per minggu sedangkan tenaga kerja bulanan mulai pukul 08.00-20.00 WITA menggunakan sistem UMR (upah minimum regional) jadi biaya yang dikeluarkan untuk upah tenaga kerja adalah Rp12.600.000 per bulan.

Konsumsi untuk tenaga kerja ditanggung oleh usaha Christine klappertaart. Karyawan diberikan libur pada hari minggu dan pada hari raya besar, adapun pengecualian pada hari minggu jika ada konsumen yang memesan maka akan dilayani tetapi bukan di outlet. karyawan berasal dari orang-orang sekitar usaha, saudara dan karyawan dari luar.

\section{Aspek hukum}

Aspek hukum usaha Christine klappertaart sadalah usaha perorangan yang di buka di daerah Jalan Yos Sudarso 140 Kairagi Weru Manado, yang tentunya sudah memiliki izin dari pemerintah daerah setempat dengan surat izin UD. cinta kasih, sehingga usaha Christine klappertaart ini hanya melakukan kesepakatan untuk menyewa outlet setiap bulannya dengan harga yang telah ditentukan. Secara hukum, keberadaan UD.cinta kasih telah terdaftar. Hal ini terbukti dengan adanya surat izin yang dimiliki UD. cinta kasih yaitu domisili usaha dengan nomor /18.06. PK/III/2011 401/2106/292/SIUP/BP2T/III/20011.

\section{Analisis aspek financial}

\section{In cash flow}

Investasi yang digunakan untuk mendirikan usaha Christine klappertaart adalah sebesar Rp200.000.000 (dua ratus juta rupiah).Digunakan untuk biaya bangunan usaha Christine klappertaart adalah sebesar Rp100.000.000, untuk modal kerja selama satu tahun sebesar Rp84.000.000 dan sisanya sebesar Rp16.000.000 digunakan untuk biaya perizinan dan sewa usaha. Sumber dana yang digunakan untuk mendirikan usaha ini seluruhnya adalah berasal dari modal sendiri.

\section{Cash flow}

Berbeda dengan in cash flow yang adalah investasi dari usaha Christine klappertaart, cash flow adalah perhitungan arus kas bersih selama umur ekonomis usaha Christine klappertaart yakni selama tiga tahun yaitu dari tahun 2012-2014 sehingga dapat dilihat bahwa selama tiga tahun usaha ini mampu untuk mencapai keuntungan dengan investasi atau penanaman modal yang telah dilakukan.

Dalam perhitungan arus kas per tahun usaha Christine klappertaart akan diperoleh arus kas bersih dari usaha ini dengan menghitung pendapatan per tahun, total penjualan per tahun, kenaikan biaya operasional, biaya penyusutan, total biaya, laba kotor, sewa outlet dan laba bersih yang diperoleh usaha Christine klappertaart selama umur ekonomis usaha.

Dengan demikian cash flow dari usaha Christine klappertaart akan dihitung berdasarkan nilai investasi yang dilakukan selama usaha ini dilaksanakan. 
Tabel 2. Perhitungan arus kas bersih per tahun usaha Christine klappertaart periode (2012-2014)

\begin{tabular}{|c|c|c|c|}
\hline \multirow[t]{2}{*}{ Keterangan } & \multicolumn{3}{|c|}{ Tahun (Rp) } \\
\hline & 1 & 2 & 3 \\
\hline $\begin{array}{l}\text { Pendapatan } \\
\text { Laba klappertaart (naik 21\% } \\
\text { per tahun) }\end{array}$ & 119.326 .933 & 151.768 .933 & 191.686 .933 \\
\hline $\begin{array}{l}\text { Nilai residu } \\
\text { Total penjualan } \\
\text { Biaya operasional (naik } 21 \% \\
\text { per tahun) }\end{array}$ & $\begin{array}{r}- \\
439.920 .000 \\
276.000 .000\end{array}$ & $\begin{array}{r}- \\
544.050 .000 \\
347.688 .000\end{array}$ & $\begin{array}{r}- \\
675.480 .000 \\
439.200 .000\end{array}$ \\
\hline $\begin{array}{l}\text { Penyusutan } \\
\text { Total biaya } \\
\text { Laba kotor (operasional) }\end{array}$ & $\begin{array}{r}26.593 .066 \\
302.593 .066 \\
137.326 .934\end{array}$ & $\begin{array}{r}26.593 .066 \\
374.281 .066 \\
169.768 .934\end{array}$ & $\begin{array}{r}26.593 .066 \\
465.793 .066 \\
209.686 .934\end{array}$ \\
\hline $\begin{array}{l}\text { Sewa outlet } \\
\text { Laba bersih (usaha) } \\
\text { Arus kas bersih (laba bersih }+ \\
\text { penyusutan }\end{array}$ & $\begin{array}{r}18.000 .000 \\
119.326 .934 \\
145.920 .000\end{array}$ & $\begin{array}{r}18.000 .000 \\
151.768 .934 \\
178.362 .000\end{array}$ & $\begin{array}{r}18.000 .000 \\
191.686 .934 \\
218.280 .000\end{array}$ \\
\hline
\end{tabular}

Pada Tabel 2. menunjukan bahwa perhitungan arus kas bersih dari tahun pertama hingga tahun ketiga selama umur ekonomis usaha Christine klappertaart ini dengan masing-masing arus kas yang didapatkan yaitu pada tahun pertama sebesar Rp145.920.000 pada tahun kedua sebesar Rp178.362.000 dan pada tahun ketiga sebesar Rp218.280.000 perhitungan arus kas dihitung berdasarkan umur ekonomis usaha Christine klappertaart yaitu selama tiga tahun, hingga diperoleh perhitungan seperti yang ditunjukan oleh Tabel 2.

\section{Kriteria kelayakan investasi}

Kriteria kelayakan investasi pada usaha Christine klappertaart adalah tolak ukur untuk dapat menyimpulkan layak atau tidaknya usaha ini dilanjtukan dan dikembangkan. Untuk menghitung layak atau tidaknya usaha ini dijalankan maka akan dilihat dari hasil perhitungan payback period $(P P)$, net present value (NPV), internal of return (IRR), dan profitability indeks (PI).

Pada umumnya ada empat metode yang biasa dipertimbangkan untuk dipakai dalam penilaian aliran kas dari suatu investasi. Umar (2000) dalam Swastawati (2011), yaitu :

\section{a. Payback period (PP)}

Payback period adalah suatu periode yang diperlukan untuk menutup kembali pengeluaran investasi (initial cash investment) yang menggunakan aliran kas, dengan kata lain payback period merupakan rasio antara initial cash investment dengan cash inflow, yang hasilnya merupakan satuan waktu. selanjutnya nilai rasio ini dibandingkan dengan maximum payback period yang dapat diterima.

\section{Tabel 3. Estimasi arus kas bersih}

\begin{tabular}{ccc}
\hline Tahun & Arus kas bersih (Rp) & $\begin{array}{c}\text { Akumulasi kas } \\
\text { masuk }\end{array}$ \\
\hline 0 & $(200.000 .000)$ & -200.000 .000 \\
1 & 145.920 .000 & -540.80 .000 \\
& & \\
3 & 178.362 .000 & 124.282 .000 \\
& 218.280 .000 & 342.562 .000 \\
\hline
\end{tabular}

Pada Tabel 3. estimasi arus kas bersih akhir tahun kedua kas masuk bersih masih kurang Rp124.282.000, padahal proceeds tahun ketiga sebesar Rp218.280.000. maka waktu untuk 
mengumpulkan proceeds pada tahun ketiga adalah 0,56 tahun yang diperoleh dari :

$$
\frac{124.282 .000}{218.280 .000} \times 1 \text { tahun }=0,56 \text { tahun }
$$

Maka perhitungannya adalah sebagai berikut :

$$
\begin{aligned}
& 0,56 \times 365=207 \text { hari } \\
& 207: 30 \text { hari }=6,92 \text { bulan } \\
& 0,92 \times 30 \text { hari }=27 \text { hari }
\end{aligned}
$$

Berdasarkan perhitungan Tabel 3. maka dalam usaha Christine klappertaart periode pengembalian investasi atau penanaman modal sebesar Rp200.000.000 sudah akan dapat diperoleh kembali oleh usaha ini seluruhnya dalam jangka waktu 2 tahun 6 bulan 27 hari. Dengan demikian usaha ini dinyatakan layak untuk dilanjutkan karena satuan waktu yang diperoleh lebih pendek dari umur ekonomis usaha Christine klappertaart yaitu tiga tahun.

\section{b. Net present value (NPV)}

Net present value yaitu selisih antara present value dari investasi dengan nilai sekarang dari penerimaan-penerimaan kas bersih di masa yang akan datang.

Tabel 4. Perhitungan net present value usaha Christine klappertaart atas dasar discount factor $18 \%$

\begin{tabular}{cccc}
\hline Tahun & $\begin{array}{c}\text { Discount factor } \\
18 \%\end{array}$ & $\begin{array}{c}\text { Arus kas bersih } \\
(\mathrm{Rp})\end{array}$ & $\begin{array}{c}\text { PV AKB } \\
(\mathrm{Rp})\end{array}$ \\
\hline 1 & 0,8474 & 145.920 .000 & 123.652 .608 \\
2 & 0,7181 & 178.362 .000 & 128.081 .752 \\
3 & 0,6086 & 218.280 .000 & 132.845 .208 \\
& PV dari Proceeds & & 384.579 .568 \\
& PV dari Outlays & & 200.000 .000 \\
\hline \multicolumn{3}{c}{ NPV }
\end{tabular}

Sumber : data primer, 2015 (diolah)

$\mathrm{NPV}=\mathrm{PV}$ dari proceeds $-\mathrm{PV}$ dari outlays

$\mathrm{NPV}=384.579 .568-200.000 .00=184.579 .568$

Berdasarkan Tabel 4. Perhitungan net present value $\mathrm{pv}$ dari proceeds adalah sebesar
Rp384.579.568, sedangkan pv dari outlays usaha sebesar Rp200.000.000 maka net present value yang diperoleh usaha adalah Rp184.579.568. maka usaha Christine klappertaart dinyatakan layak untuk dilanjutkan karena net present value yang dihasilkan berdasarkan perhitungan positif.

\section{c. Internal rate of return}

Metode ini digunakan untuk mencari tingkat bunga yang menyamakan nilai sekarang dari arus kas yang diharapkan di masa datang, atau penerimaan kas, dengan mengeluarkan investasi awal. IRR adalah salah satu metode untuk mengukur tingkat investasi.

Metode internal rate of return dapat didefinisikan sebagai tingkat bunga yang akan menjadikan jumlah nilai sekarang dari proceed yang diharapkan akan diterima $p v$ (of future proceeds) sama dengan jumlah sekarang dari pengeluaran modal ( $p v$ of capital outlays).

\begin{tabular}{|c|c|c|c|}
\hline Tahun & Keterangan & $\begin{array}{l}\text { Arus kas } \\
\text { bersih }\end{array}$ & $\begin{array}{l}\text { Batas tidak layak } \\
<18 \%\end{array}$ \\
\hline 0 & $\begin{array}{l}\text { Initial Invest- } \\
\text { ment/Otlays }\end{array}$ & $\begin{array}{c}- \\
200.000 .000\end{array}$ & $\begin{array}{l}- \\
20000000018.00 \%\end{array}$ \\
\hline 1 & $\begin{array}{c}\text { Proceeds Tahun } \\
\text { ke-1 }\end{array}$ & 145.920 .000 & $14591999982.00 \%$ \\
\hline 2 & $\begin{array}{c}\text { Proceeds Tahun } \\
\text { ke-2 }\end{array}$ & 178.362 .000 & $17836199982.00 \%$ \\
\hline 3 & $\begin{array}{l}\text { Proceeds Tahun } \\
\text { ke-3 }\end{array}$ & 218.280 .000 & $21827999982.00 \%$ \\
\hline IRR & & $66 \%$ & $66 \%$ \\
\hline
\end{tabular}

Tabel 5. Analisis kelayakan usaha Christine klappertaart dengan internal rate of return

Sumber : data primer, 2015 (diolah)

Berdasarkan hasil analisis Tabel 5. internal rate of return yang dihasilkan oleh usaha Christine klappertaart dengan menggunakan microsoft excel adalah sebesar $66 \%$.

Selain perhitungan internal rate of return menggunakan microsoft excel, hasil perhitungan internal rate of retun pada usaha Chritine klappertaart juga dapat dihitung dengan mengunakan rumus matematis. Rumus yang digunakan untuk menghitung IRR adalah sebagai berikut : 


$$
\text { atau IRR }=\frac{\text { total laba usaha }}{\text { Modal Sendiri }}
$$

\section{Tabel 6. Analisis kelayakan usaha Christine klappertaart dengan internal rate of retun}

\begin{tabular}{crrr}
\hline Keterangan & \multicolumn{3}{c}{ Tahun (Rp) } \\
\cline { 2 - 4 } & 1 & \multicolumn{3}{c}{2} & \multicolumn{1}{c}{3} \\
\hline Penerimaan & 439.920 .000 & 544.050 .000 & 675.480 .000 \\
Total biaya & 320.593 .066 & 392.281 .066 & 483.793 .066 \\
produksi & & & \\
Pendapatan & 119.326 .933 & 151.768 .933 & 191.686 .933 \\
Outlays & 200.000 .000 & 200.000 .000 & 200.000 .000 \\
Laba usaha & 80.673 .067 & 48.231 .067 & 8.313 .067 \\
\hline
\end{tabular}

Sumber : data primer, 2015 (diolah)

$$
\begin{aligned}
& \mathrm{IRR}=\frac{\text { total laba usaha }}{\text { Outlays }} \times 100 \% \\
& \mathrm{IRR}=\frac{137.217 .201}{200000000} \times 100 \%=68 \%
\end{aligned}
$$

Berdasarkan perhitungan analisis internal rate of return Tabel 5 dan Tabel 6 internal rate of return yang diperoleh usaha Christine Klappertaart adalah 66\%. Berarti modal sendiri sebesar Rp200.000.000 mampu mendorong usaha ini menghasilkan laba sebesar $66 \%$.

Dengan demikian maka usaha Christine klappertaart dinyatakan layak untuk dilanjutkan karena internal rate of return lebih besar dari tingkat suku bunga yang ditentukan yaitu $18 \%$.

\section{d. Profitability indeks}

Metode ini digunakan dengan menghitung pebandingan antara nilai sekarang (dari penerimaan-penerimaan kas bersih di masa yang akan datang) dengan nilai sekarang dari investasi.

Kriteria ini erat hubungannya dengan kriteria NPV, jika NPV suatu proyek dikatakan layak (NPV $>0)$, maka menurut kriteria PI juga layak (PI > 1) karena keduanya variabel sama.

\section{Tabel 7. Analisis kelayakan usaha Christine klappertaart dengan profitability indeks}

\begin{tabular}{cccc}
\hline Tahun & Diskount Faktor & $\begin{array}{c}\text { Arus kas ber- } \\
\text { sih }\end{array}$ & PV dari AKB \\
\hline 1 & 0,8474 & 145.920 .000 & 123.652 .608 \\
2 & 0,7181 & 178.362 .000 & 128.081 .752 \\
3 & 0,6086 & 218.280 .000 & 132.579 .568 \\
& PV dari & 384.579 .568 \\
& Proceeds & \\
& PV dari Outlays & 200.000 .000 \\
\hline \multicolumn{3}{c}{ NPV } & 184.579 .568 \\
\hline
\end{tabular}

Sumber : data primer, 2015 (diolah)

$$
\begin{aligned}
& \text { Profitability indeks }=\frac{P V \text { Proceeds }}{P V \text { Outlays }} \\
& \text { Profitability indeks }=\frac{384.579 .568}{200.000 .000}=1,92
\end{aligned}
$$

Berdasarkan perhitungan profitability indeks tabel 6 menunjukan bahwa net present value yang bernilai positif sebesar Rp184.579.568, maka usaha Christine Klappertaart memperoleh hasil perhitungan profitability indeks sebesar 1,92. Dengan demikian profitability insdeks yang diperoleh usaha Christine Klappertaart dinyatakan layak karena oleh kriteria penilaian berdasarkan profitability indeks yaitu, apabila PI > 1 maka proyek dinyatakan layak.

\section{Hasil analisis aspek kelayakan usaha Christine klappertaart}

Dari hasil perhitungan in cash flow, cash flow, hingga kriteria kelayakan investasi yang telah dilakukan, dapat disimpulkan layak atau tidaknya usaha Christine klappertaart untuk terus dilaksanakan hingga pada pengembangan usaha ini.Sehingga dapat dilihat dari dua aspek yakni aspek non-financial dan aspek financial. 
Tabel 8. Hasil analisis aspek kelayakan nonfinancial usaha Christine klappertaart

\begin{tabular}{|c|c|c|c|}
\hline $\begin{array}{l}\mathrm{N} \\
\mathrm{o}\end{array}$ & $\begin{array}{l}\text { Kriteria } \\
\text { kelayakan } \\
\text { non- } \\
\text { financial }\end{array}$ & $\begin{array}{c}\text { Hasil } \\
\text { analisis }\end{array}$ & Keterangan \\
\hline 1. & $\begin{array}{l}\text { Aspek } \\
\text { pasar \& \& } \\
\text { pemasaran }\end{array}$ & Layak & $\begin{array}{l}\text { besarnya potensi pasar } \\
\text { dilihat dari bauran } \\
\text { pemasaran yang telah } \\
\text { diamati. }\end{array}$ \\
\hline 2. & $\begin{array}{l}\text { Aspek } \\
\text { teknis/ } \\
\text { teknologis }\end{array}$ & Layak & $\begin{array}{l}\text { lokasi outlet usaha ini } \\
\text { sangat srategis. }\end{array}$ \\
\hline 3. & $\begin{array}{l}\text { Aspek } \\
\text { sumber } \\
\text { daya manu- } \\
\text { sia }\end{array}$ & Layak & $\begin{array}{l}\text { tenaga kerja tidak men- } \\
\text { galami kendala selama } \\
\text { proses produksi. }\end{array}$ \\
\hline 4. & $\begin{array}{l}\text { Aspek ho- } \\
\text { kum }\end{array}$ & Layak & $\begin{array}{l}\text { Surat izin dengan nama } \\
\text { UD. Cinta Kasih dengan } \\
\text { nomor izin usaha } \\
\text { /18.06.PK/III/2011401/2 } \\
\text { 106/292/SIUP/BP2T/I/2 } \\
0011 \text {. }\end{array}$ \\
\hline
\end{tabular}

Sumber : data primer, 2015 (diolah)

Berdasarkan Tabel 8, hasil analisis kelayakan non-financial usaha Christine klappertaart, dengan aspek-aspek yang diamati maka usaha ini dinyatakan layak untuk dilanjutkan.

Tabel 9. Hasil analisis aspek kelayakan financial usaha Christine klappertaart

\begin{tabular}{ccccc}
\hline No. & $\begin{array}{c}\text { Kriteria ke- } \\
\text { layakan inves- } \\
\text { tasi }\end{array}$ & $\begin{array}{c}\text { Hasil ana- } \\
\text { lisis }\end{array}$ & $\begin{array}{c}\text { Ket- } \\
\text { erangan }\end{array}$ & $\begin{array}{c}\text { Tidak } \\
\text { layak }\end{array}$ \\
\hline 1. & Payback period & $\begin{array}{c}\text { 2 tahun enam } \\
\text { bulan 27 hari } \\
\text { Rp184.579.56 }\end{array}$ & Layak & $\begin{array}{c}>3 \\
\text { Lahun }\end{array}$ \\
2. & $\begin{array}{c}\text { Net present } \\
\text { value }\end{array}$ & $\begin{array}{c}\text { Negati } \\
\mathrm{f}\end{array}$ \\
3. & $\begin{array}{c}\text { Internal rate of } \\
\text { return }\end{array}$ & $66 \%$ & Layak & $<66 \%$ \\
4. & $\begin{array}{c}\text { Profitability } \\
\text { index }\end{array}$ & 1,92 & Layak & $<1$ \\
& & & \\
\hline
\end{tabular}

Sumber : data primer, 2015 (diolah)

Berdasarkan hasil analisis kelayakan financial pada Tabel 9. menyatakan bahwa usaha ini memiliki NPV sebesar Rp184.579.568 yang berarti bahwa usaha ini akan memberikan keuntungan sebesar Rp184.579.568 selama 3 tahun menurut nilai waktu uang sekarang.
Nilai IRR adalah sebesar $66 \%$ yang berarti lebih besar dibandingkan dengan tingkat suku bunga $18 \%$. Nilai profitability indeks sebesar 1,92 yang berarti layak karena lebih besar dari 1. Hasil analisis payback period menunjukan bahwa untuk mengembalikan nilai investasi sebesar Rp200.000.000, memerlukan waktu 2 tahun 6 bulan 27 hari.

Dengan demikian berdasarkan perhitungan kelayakan investasi dan hasil analisis kelayakan financial dan non-financial maka dapat disimpulakan bahwa usaha Christine klappertaart setelah tiga tahun usaha, telah balik modal pada tahun kedua dari investasi yang ditanamkan selama umur ekonomis usaha ini selama tiga tahun.

\section{KESIMPULAN DAN SARAN}

\section{Kesimpulan}

Berdasarkan hasil analisis kriteria kelayakan non financial pada usaha Christine klappertaart, maka aspek-aspek didalamnya antara lain aspek pasar, aspek teknis, aspek manajemen, aspek hukum, dan aspek keuangan pada usaha ini dinyatakan layak untuk dilanjutkan.

Hasil analisis kelayakan financial dengan $100 \%$ modal sendiri dinyatakan layak, dengan nilai net present value yang positif pada diskon factor $18 \%$, internal rate of return lebih besar dari tingkat suku bunga yang ditentukan yaitu $18 \%$, dengan nilai profitability indeks lebih besar dari satu. payback period menunjukan bahwa usaha Christine klappertaart telah mengembalikan investasinya dalam waktu 2 tahun enam bulan 27 hari.

\section{Saran}

Dari segi financial usaha ini layak dilanjutkan maka sebaiknya usaha ini dapat meningkatkan investasi dengan menambah produk kue-kue berbahan baku kelapa. Dengan demikian usaha ini telah layak dikembangkan untuk menaikan produksi dan kapasitas yang besar serta orientasi ekspor. 


\section{DAFTAR PUSTAKA}

Aji, B, P., 2012. Strategi pengembangan agroindustri keripik pisang di kecamatan tawangmangu kabupaten karanganyar.e-Jurnal - ISSN 23021713 Volume 1 Nomor 2 Tahun 2012. Program studi Agribisnis Fakultas Pertanian Universitas Sebelas Maret Surakarta

Andrianto, T, T., 2014.Pengantar ilmu petanian agraris, agrobisnis, agroindustri, dan agroekotegnologi. PT GLOBAL PUSTAKA UTAMA Yogyakarta

Arifin J dan Syukri M., 2006. Aplikasi excel dalam bisnis perbankan terapan. PT Elex Media Komputindo. Jakarta J.,2007. Aplikasi excel dalam studi kelayakan bisnis. PT Elex Media Komputindo Kelompok Gramedia , Anggota IKAPI Jakarta J.,2008. Aplikasi excel untuk perencanaan bisnis (Business Plan). Cetakan Kedua. PT Elex Media Komputindo Kelompok Gramedia Anggota IKAPI Jakarta

Halim, A., 2005. Analisis investasi.Salemba Empat, Jakarta

Hanafie, R., 2010. Pengantar ekonomi pertanian. CV ANDI OFFSET. Yogyakarta 55281

Husnan, S dan Suwarsono., 2000. Studi kelayakan proyek.Unit penerbit dan pencetak AMP YPKN. Yogyakarta

Ibrahim, Y., 2009. Studi kelayakan bisnis.Cetakan ketiga. PT RINEKA CIPTA, Jakarta

Jumingan., 2014. Studi kelayakan bisnis teori dan pembuatan proposal kelayakan. PT. Bumi Aksara Jl Sawo Raya N0. 18 Jakarta 13220

Kasmir, 2008. Pemasaran bank. Edisi revisi cetakan ke-3. KENCANA PREDANA MEDIA GROUP. J1 Tambra Raya No 23 Rawamangun Jakarta 13220

Kotler P, dan Amstrong G., 2008. Prinsip-prinsip pemasaran Jilid 1. Erlangga, Jakarta ., 2009.Manajemen pemasaran.Jilid 1 Edisi 13.Erlangga Jakarta

Kristanto, H, R., 2009. Kewirausahaan entrepreneurship pendekatan manajemen dan praktik.Edisi pertama cetakan pertama. Candi gerbang permai blok R/6 Yogyakarta 55511.
Kusnandar, T, M dan Wibowo A., 2010. Manajemen agroindustri, kajian teori dan model kelembagaan agroindustri skala kecil pedesaan.Cetakan 1.Surakarta. UNS Press

Primasatya, A, G., 2014.Riset pasar untuk memulai usaha baru.Skripsi Universitas Atma Jaya Yogyakarta.Fakultas Teknik Industri Program Studi Teknik Industri Yogyakarta

Rachadian F,M, Agassi E,A Sutopo W., 2013. Analisis kelayakan investasi penambahan mesin frais baru pada CV. XYZ. J@TI Undip, Vol VIII, No 1, Januari 2013. Jurusan Teknik Industri, Universitas Sebelas Maret. Ejournal.undip.ac.id/index.php/jgti/article/viewFile/4 774/4319. 10 Mei 2015

Subagyo, A., 2007. Studi kelayakan teori dan aplikasi. PT Elex Media Komputindo Kelompok Gramedia, Jakarta .2008. Studi kelayakan teori dan aplikasi.Edisi 2. PT Elex Media Komputindo Kelompok Gramedia , Jakarta

Sukino., 2013. Membangun pertanian dengan pemberdayaan masyarakat tani terobosan menanggulangi kemiskinan. Pustaka baru press, Yogyakarta

Suliyanto., 2010. Studi kelayakan bisnis. CV ANDI OFFSET. Yogyakarta 55281

Sunyoto D., 2014.Studi kelayakan bisnis.Cetakan pertama. CAPS (Center of academic Publishing Service). Jakarta 12620

Swastawati, F., 2011. Studi kelayakan dan efisiensi usaha pengasapan ikan dengan asap cair limbah pertanian. Jurnal dinamika ekonomi pembangunan.Juli 2011 volume 1 nomor 1.Fakultas perikanan dan ilmu kelautan. Universittas Diponegoro Semarang

Syachroni A., 2010. Pengaruh biaya bauran promosi terhadap volume penjualan rumah metland tambun pada PT. Metropolitan land terbuka. Skripsi

Umar Hardian (Penterjemah). 2000. Research methods in finance and banking. PT. Gramedia pustaka utama. Jakarta ., 2003.Metode riset bisnis.Edisi 2. PT Gramedia pustaka utama, Jakarta .,2005. Studi kelayakan bisnis.Edisi 3. PT Gramedia pustaka utama, Jakarta

Widjajanta B, Widyaningsih A, Tanuatmodjo H., 2007. Mengasah kemampuan ekonomi.Cetakan pertama.Citra praya. Bandung 40224 